\title{
T3c Stage Finding
}

National Cancer Institute

\section{Source}

National Cancer Institute. T3c Stage Finding. NCI Thesaurus. Code C48731.

A general term that refers to a TNM finding of a primary tumor usually indicating that the cancer is locally invasive. The definition of T3c TNM finding depends on the specific type of cancer that it refers to; for example, for kidney cancer it refers to a primary tumor that grossly extends into the vena cava above the diaphragm, or invades the wall of the vena cava; for fallopian tube cancer it refers to a primary tumor with peritoneal metastasis outside the pelvis measuring more than $2 \mathrm{~cm}$ in diameter; for melanoma of the conjunctiva it refers to a primary tumor invading the orbit. 